\title{
The impact of COVID-19 restrictions on older adults' loneliness: Evidence from high-frequency panel data
}

\author{
Erwin Stolz* \\ Hannes Mayerl* \\ Wolfgang Freidl*
}

Dezember 15, 2021

\begin{abstract}
BACKGROUND: It is unclear how strong and long lasting the effects of recurring COVID-19 restrictions on older adults' loneliness are.

METHODS: 469 retired older adults (60+) provided 8,814 repeated observations of loneliness (27 waves) in the Austrian Corona Panel Project between March 2020 and December 2021. Ordinal mixed regression models were used to estimate the effect of the stringency of COVID-19 restrictions (SI) on loneliness.

RESULTS: The proportion of older adults who reported to be often lonely correlated closely $(\mathrm{r}=0.63)$ with the SI over time: both peaked during lockdowns ( $\mathrm{SI}=82$, often lonely $=10-12 \%)$ and were lowest during the summer of 2020 (SI=36, often lonely=5$6 \%$ ). Results from regression models indicate, that when the SI increased above 60 (=strict lockdown), an increase in loneliness followed. Older adults who lived alone were more affected than those living with others.

CONCLUSIONS: Stringent COVID-19 restrictions lead to situational loneliness, particularly among those who lived alone. Efforts should be made to enable older adults who live alone to have save in-person contact during lockdown periods.
\end{abstract}

Keywords: loneliness, older adults, covid-19 pandemic, restrictions, lockdowns

\section{Introduction}

After almost two years, the pandemic Coronavirus disease 2019 (COVID-19) still represents an acute global health threat. To break waves of exponential COVID-19 infection rates and

*Institute of Social Medicine and Epidemiology, Medical University of Graz, Graz, Austria 
to avoid overburdening hospital care, many governments repeatedly responded with an array of containment and closure policies. By restricting in-person social contacts, these public health interventions may lead to negative psychosocial side effects among older adults such as increased loneliness, which can be defined as a perceived discrepancy between the desired and one's existing social relationships (Peplau \& Perlman, 1982). Older adults already face an increased risk of loneliness due to loss of partners and peers or health-problems (e.g. Luhmann \& Hawkley, 2016; Savikko et al., 2005), and loneliness has long been considered harmful to older adults' physical and mental health (Courtin \& Knapp, 2017). Therefore, loneliness induced by pandemic restrictions is a current subject of concern.

Whether and how strongly COVID-19 restrictions have affected older adults is not yet clear though. While some studies (Krendl \& Perry, 2021; Luchetti et al., 2020; Macdonald \& Hülür, 2021; Stolz et al., 2021; Tilburg et al., 2021; Wong et al., 2020) suggest an increase in loneliness during the first wave of the pandemic compared to pre-pandemic times, others (Hansen et al., 2021; Kivi et al., 2021; Peng \& Roth, 2021; Röhr et al., 2020) found no changes. We know even less about how loneliness levels changed after the first lockdown(s). Studies with multiple measurement points during the early pandemic (Buecker et al., 2020; Kotwal et al., 2021; Luchetti et al., 2020; Stolz et al., 2021) suggest that loneliness was higher during and immediately after the first lockdown, but leveled off thereafter. Older adults who live alone could be particularly affected by restrictions that limit in-person contacts with individuals from outside the household compared to those who live together with their partner or children. Indeed, a few studies reported that early-pandemic increases in loneliness were higher among older adults who lived alone (Stolz et al., 2021; Wong et al., 2020) or were un-partnered (Hansen et al., 2021; Tilburg et al., 2021), but it is unclear whether these findings extend throughout the later pandemic. Importantly, none of these studies directly measured the duration and stringency of pandemic restrictions, although these varied considerably between countries and over time.

In sum, we currently know rather little about later periods of the pandemic: It is unclear how strong and long lasting the effects of COVID-19 restrictions on older adults' loneliness are, and how profoundly older adults who live alone were affected. The current study attempts to answer these questions based on high-frequency survey panel data which allows to monitor older adults' loneliness continuously throughout the COVID-19 pandemic. 


\section{Methods}

\section{Data}

Data came from the Austrian Corona Panel Project (Kittel et al., 2021), an online panel survey conducted by the University of Vienna between late March 2020 and early December 2021. Respondents were quota sampled from a pre-existing online panel based on key demographics, and 27 waves of online interviews have been completed so far. For the current study, we used data from 469 retired participants $60+$ who provided a total of 8,814 repeated measurements ( $=21$ interviews per person on average).

\section{Variables}

Loneliness was measured with the same single item in each wave: participants were asked how often they felt lonely during the last week. Possible answer categories included 'never,' 'on some days,' 'multiple times a week,' 'almost every day,' and 'every day.' Due to the limited proportion of answers in the last three categories $(3.7 \%, 2.1 \%$, and $1.9 \%)$, these were collapsed into a single category ('often lonely').

Individual-level predictor variables included the time of interview since baseline (in weeks), and five time-invariant variables referring to February 2020: living alone (no/yes), age (in years), sex (male/female), high school education (no/yes), and chronic disease(s) (no/yes). 12 participants $(2.6 \%)$ had missing values in these variables, which was addressed by multiple imputation (R-package mice, 3 imputed datasets).

To measure the stringency of pandemic-related restrictions, we used the COVID-19 Government Response Stringency Index (SI, Hale et al., 2021) as a time-varying, country-level predictor. The SI is a sum index based on nine ordinal measures (school closing, workplace closing, canceling of public events, restriction gatherings, public transport closing, stay at home requirements, restrictions on internal movement, international travel control, and public information campaigns) that quantifies pandemic-related containment and closure policies, ranging from 0 (no restrictions) to 100 (maximum restrictions). Since the loneliness item refers to the last week before each interview, we averaged daily SI values during the last seven days before the interview. 
medRxiv preprint doi: https://doi.org/10.1101/2021.12.15.21267860; this version posted December 16, 2021. The copyright holder for this preprint (which was not certified by peer review) is the author/funder, who has granted medRxiv a license to display the preprint in perpetuity.

It is made available under a CC-BY-NC-ND 4.0 International license .

\section{Statistical Analysis}

We modeled the impact of time-varying SI on repeatedly measured loneliness using cumulative ordinal mixed regression models (Bürkner \& Vuorre, 2019). We used a natural cubic spline to account for non-linear effects of the SI. Our core interest is in the overall effect of SI on loneliness (model 1), but also whether this effect is moderated by living alone. Since the relationship between living alone and loneliness might be confounded by socio-demographics and health (Cudjoe et al., 2020; Steptoe et al., 2013), we adjusted for these in model 2, and compared the model fit (Watanabe-Akaike Information Criterion (WAIC) and leave-one-out cross-validation (LOO) (Vehtari et al., 2017)) with model 3, where we added the interaction effect between SI and living status. For all analyses, we applied demographic weights. Regression models were estimated with brms (v2.16.1), a front-end for RStan (v2.21.2). All analyses were conducted in $R$ (v4.1.2).

Figure 1: Prevalence of loneliness (March 2020 - December 2021)

\section{How often have you been lonely last week?}

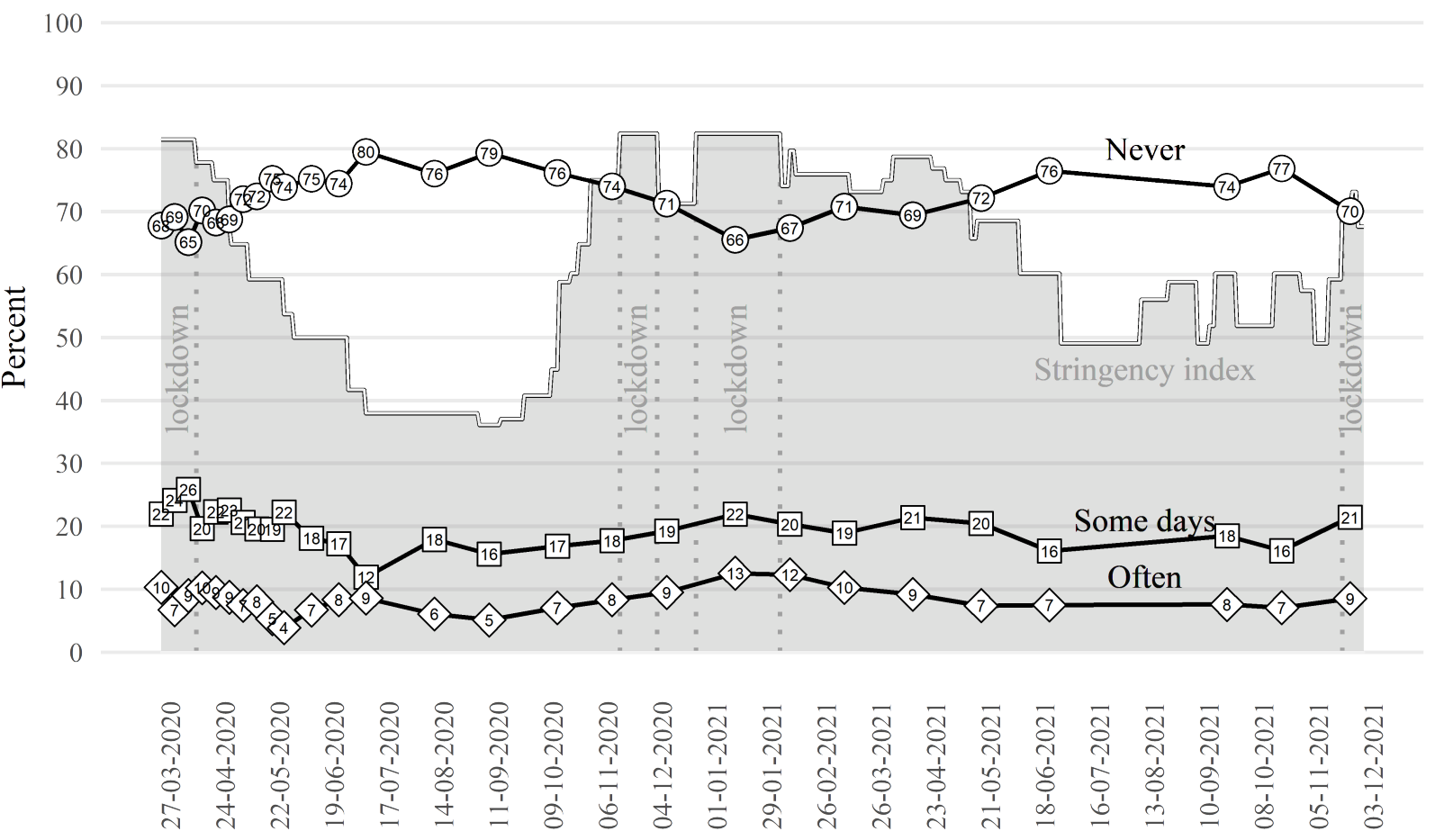

$\mathrm{n}=469$, weighted data. Figure shows trajectories of the prevalence of the three categories (never, some days, often) of loneliness (black lines) in \% by wave. Grey background shows the stringency index (SI), dotted vertical lines indicate the duration of strict lockdowns. 
medRxiv preprint doi: https://doi.org/10.1101/2021.12.15.21267860; this version posted December 16, 2021. The copyright holder for this preprint (which was not certified by peer review) is the author/funder, who has granted medRxiv a license to display the preprint in perpetuity.

It is made available under a CC-BY-NC-ND 4.0 International license .

\section{Results}

The median age of the sample was $69(\mathrm{IQR}=8$, range=60-85) years, $57.8 \%$ were women, $16.4 \%$ had completed high school education, $42.2 \%$ had one or more chronic disease(s), and $32.8 \%$ lived alone before the onset of the pandemic. COVID-19 restrictions varied considerably during the pandemic in Austria (Figure 1): they peaked ( $\mathrm{SI}=82$ ) during the first three lockdown periods and were lowest during the summer months of 2020 (SI=36) and 2021 $(\mathrm{SI}=49)$. Figure 1 also describes the trajectories of the prevalence of loneliness categories. It shows that the proportion of older adults who felt often lonely reached its maximum of 10-12\% during and after the two longer lockdowns, but decreased soon thereafter. During the summer months of 2020, when restrictions were lowest, only 5-6\% reported to be often lonely. The correlation coefficient between the SI and the prevalence of feeling often lonely across waves was $r=0.63$. This pattern varied by living status (Figure 2): Older adults who lived alone were not only more likely to report feeling often lonely on average (maximal proportion was 18-21\% during lockdowns), but their loneliness was also more tethered to the SI $(r=0.62)$ compared to those who lived together with others $(r=0.28)$.

Results from the regression model (Supplementary Table 1) indicate that loneliness decreased over time, and that the SI was non-linearly associated with feeling lonelier (Figure 3): increases in SI above 60 - i.e. the introduction of a strict lockdown - were associated with considerable increases in loneliness. Including the interaction effect between SI and living alone improved the model fit and indicates that older adults who lived alone were more likely to feel often lonely as SI increased compared to those who lived with others.

\section{Discussion}

In this paper, we monitored loneliness among retired older adults 60+ in Austria throughout the pandemic to assess the impact of COVID-19 restrictions. We found that when pandemic restrictions became more stringent - particularly when a strict lockdown was introduced the prevalence of loneliness increased. Soon after restrictions were loosened, however, the prevalence of loneliness again decreased. A particularly strong impact of the restrictions on loneliness showed for older adults who lived alone.

Our findings are compatible with evidence that loneliness among older adults was higher during the early pandemic compared to pre-pandemic times (Krendl \& Perry, 2021; Luchetti et al., 2020; Macdonald \& Hülür, 2021; Stolz et al., 2021; Tilburg et al., 2021; Wong et al., 
medRxiv preprint doi: https://doi.org/10.1101/2021.12.15.21267860; this version posted December 16, 2021. The copyright holder for this preprint (which was not certified by peer review) is the author/funder, who has granted medRxiv a license to display the preprint in perpetuity.

It is made available under a CC-BY-NC-ND 4.0 International license .

Figure 2: Prevalence of loneliness by living status (March 2020 - December 2021)

A. Living alone

How often have you been lonely last week?

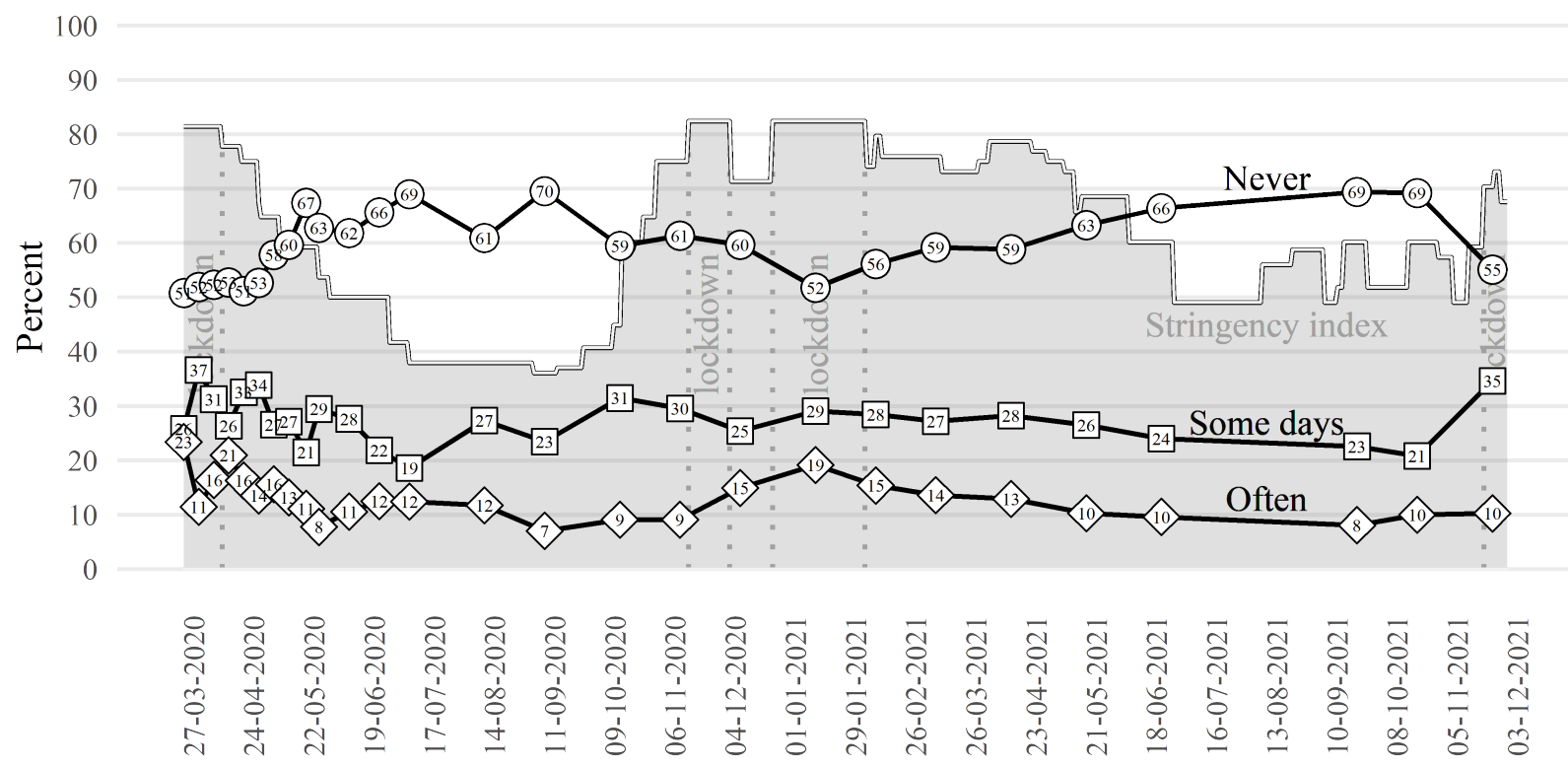

B. Living with others

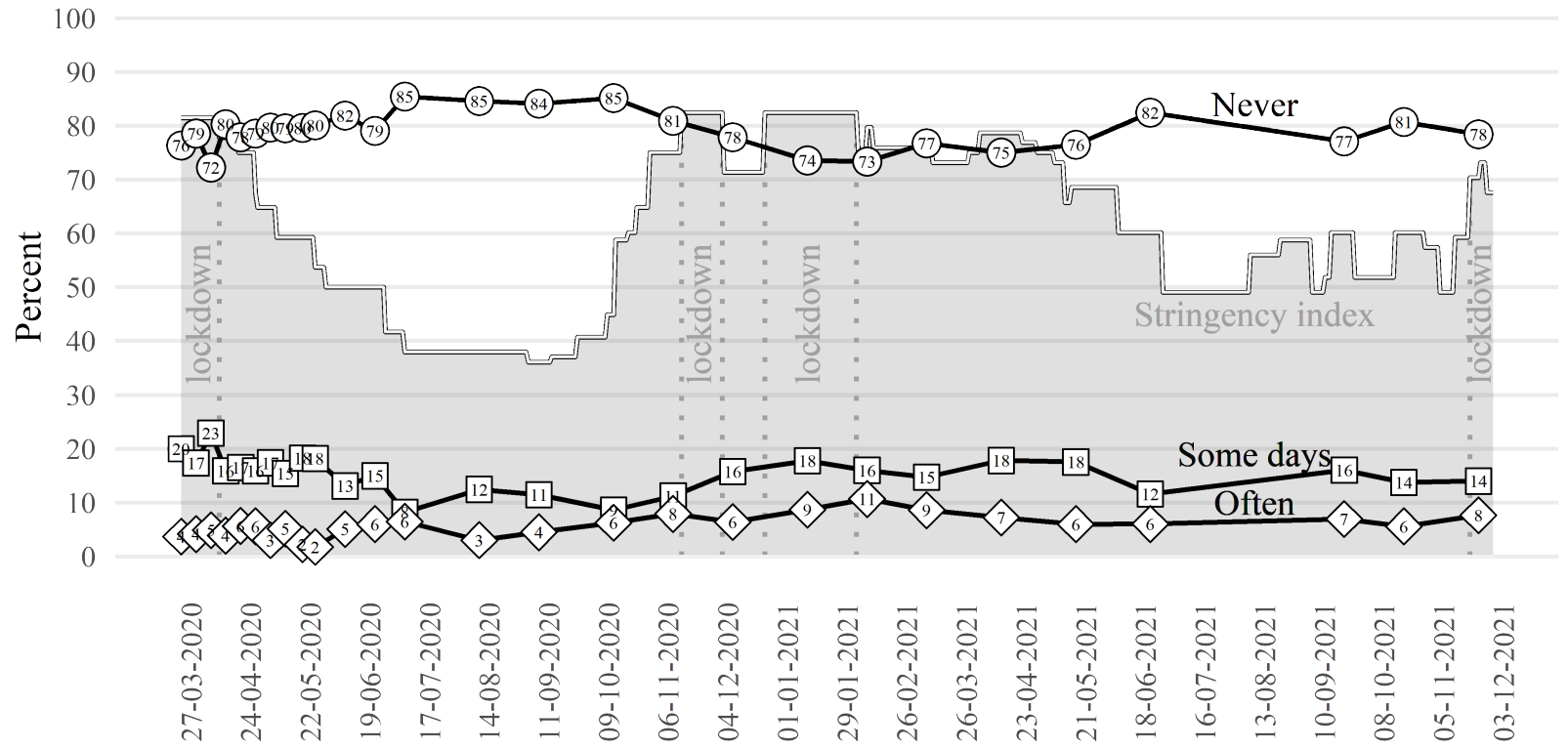

Weighted data. Figure shows trajectories of the prevalence in $\%$ of the three categories of loneliness (black lines) for those who lived alone (plot $\mathrm{A}, \mathrm{n}=166$ ) and for those who lived with others (plot $\mathrm{B}, \mathrm{n}=303)$. Grey background shows the stringency index (SI), dotted vertical lines indicate the duration of strict lockdowns. 
medRxiv preprint doi: https://doi.org/10.1101/2021.12.15.21267860; this version posted December 16, 2021. The copyright holder for this preprint (which was not certified by peer review) is the author/funder, who has granted medRxiv a license to display the preprint in perpetuity.

It is made available under a CC-BY-NC-ND 4.0 International license .

Figure 3: Predicted probability of loneliness
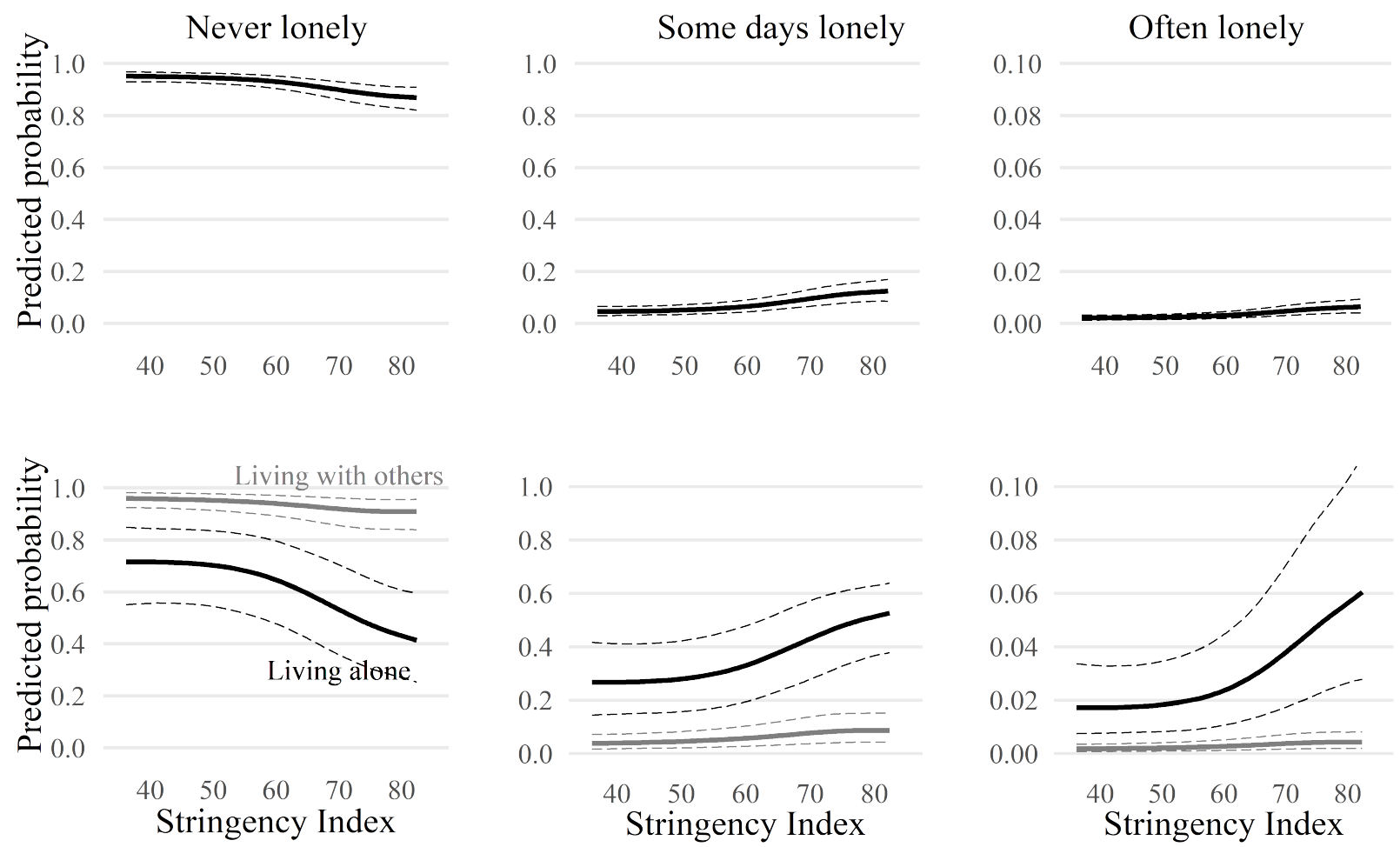

Results based on ordinal mixed regression models (first row $=$ model 1 , second row $=$ model 3 ) based on weighted data. Solid lines are predicted probability estimates based on the populationlevel effects for women of mean age, without high school-level education, and with chronic diseases during the mean point during follow-up. Dashed lines are $95 \%$ credible intervals. 
2020). Our study extends these findings for subsequent lockdowns and later periods of the pandemic. Unlike Hansen et al. (2021), we found no evidence for strong differences in the effect of restrictions on loneliness between waves or lockdowns. Instead, we confirmed findings of longitudinal studies from the early pandemic (Buecker et al., 2020; Kotwal et al., 2021; Luchetti et al., 2020; Stolz et al., 2021), insofar that increases in loneliness due to lockdowns seem rather short-lived and ceased after restrictions were lifted. We found no evidence that loneliness generally increased or that it chronified over the course of the pandemic. Restriction-induced loneliness can hence be described as mostly situational, which is less of a risk factor for negative long-term health outcomes in comparison to chronic loneliness (Martín-María et al., 2021; Shiovitz-Ezra \& Ayalon, 2010). Nonetheless, pandemic-induced loneliness may already have had short-term negative mental health consequences: Mayerl et al. (2021) and Krendl \& Perry (2021), for example, reported pandemic-related loneliness to predict depression and anxiety symptoms among older adults.

Our results imply an increase in loneliness among older adults living alone, who account for about one third of the older population aged $65+$ (e.g. Cudjoe et al., 2020). This is in line with findings from the early pandemic, that older adults who live alone had fewer in-person contacts and provided or received less help from others (Fingerman et al., 2021), and that pandemic-related increases in loneliness were higher among them (Stolz et al., 2021; Wong et al., 2020), as well as among those who were un-partnered (Hansen et al., 2021; Tilburg et al., 2021). Therefore, efforts should be made to enable older adults who live alone to have save forms of in-person contact during lockdown periods (Fingerman et al., 2021) to stay socially connected.

Despite a number of strengths (high frequency panel data, fine-grained measure of restrictions, appropriate statistical model for categorical longitudinal data), there are also several limitations to this study. First, we lacked a pre-pandemic baseline of loneliness (without restrictions) for comparison. Second, loneliness was measured with a direct, single item: Although frequently used and often highly correlated with established multiple-item scales, single items are less reliable and may lead to underestimation due to the negative connotations of the term 'loneliness.' Third, it is unlikely that the sample is representative for the population of older adults with regard to loneliness. Older adults, particularly the oldest old and institutionalized individuals, and those with a low level of education - all of which are more likely to be lonely (Cudjoe et al., 2020; Steptoe et al., 2013), particularly during the current pandemic - are difficult to recruit for online interviews (Kelfve et al., 2020). Despite the use of demographic weights, these limitations likely resulted in an underestimation of 
medRxiv preprint doi: https://doi.org/10.1101/2021.12.15.21267860; this version posted December 16, 2021. The copyright holder for this preprint (which was not certified by peer review) is the author/funder, who has granted medRxiv a license to display the preprint in perpetuity.

It is made available under a CC-BY-NC-ND 4.0 International license .

the prevalence of loneliness, which may also down-bias our SI effect estimates.

In conclusion, we found that pandemic restrictions lead to situational loneliness among older adults, particularly among those who lived alone.

\section{Conflict of Interest}

None declared.

\section{Data and code availability}

Data from the Austrian Corona Panel Project are freely available for scientific research via the Austrian Social Science Data Archive (AUSSDA). The R-Markdown code reproducing all analyses, results and this manuscript is available online via OSF.

\section{Funding}

The authors received no specific funding for conducting this study. The data collection for the ACPP has been made possible by COVID-19 Rapid Response Grant EI-COV20-006 of the Wiener Wissenschafts- und Technologiefonds (WWTF) and financial support by the rectorate of the University of Vienna. Further funding by the Austrian Social Survey (SSÖ), the Vienna Chamber of Labour (Arbeiterkammer Wien), and the Federation of Austrian Industries (Industriellenvereinigung) is gratefully acknowledged. From October 2020, ACPP continues as a research project funded by the Austrian Science Fund (Grant P33907).

\section{Author Contributions}

E.S. planned the study, performed all statistical analysis, and wrote the article. H.M. contributed to the interpretation of results and critically reviewed the manuscript. W.F. also critically reviewed the manuscript.

\section{References}

Buecker, S., Horstmann, K. T., Krasko, J., Kritzler, S., Terwiel, S., Kaiser, T., \& Luhmann, M. (2020). Changes in daily loneliness for german residents during the first four weeks of the COVID-19 pandemic. Social Science \& Medicine (1982), 265, 113541. https://doi.org/10.1016/j.socscimed.2020.113541

Bürkner, P.-C., \& Vuorre, M. (2019). Ordinal regression models in psychology: A tutorial. Advances in Methods and Practices in Psychological Science, 2(1), 77-101. https://doi.org/10.1177/2515245918823199 
Courtin, E., \& Knapp, M. (2017). Social isolation, loneliness and health in old age: A scoping review. Health 65 Social Care in the Community, 25(3), 799-812. https://doi.org/10.1111/hsc.12311

Cudjoe, T. K. M., Roth, D. L., Szanton, S. L., Wolff, J. L., Boyd, C. M., \& Thorpe, R. J. (2020). The epidemiology of social isolation: National health and aging trends study. The Journals of Gerontology: Series B, 75(1), 107-113. https://doi.org/10.1093/geronb/gby037

Fingerman, K. L., Ng, Y. T., Zhang, S., Britt, K., Colera, G., Birditt, K. S., \& Charles, S. T. (2021). Living alone during COVID-19: Social contact and emotional well-being among older adults. The Journals of Gerontology: Series B, 76 (3), e116-e121. https://doi.org/10.1093/geronb/gbaa200

Hale, T., Angrist, N., Goldszmidt, R., Kira, B., Petherick, A., Phillips, T., Webster, S., Cameron-Blake, E., Hallas, L., Majumdar, S., \& Tatlow, H. (2021). A global panel database of pandemic policies (oxford COVID-19 government response tracker). Nature Human Behaviour, 5(4), 529-538. https: //doi.org/10.1038/s41562-021-01079-8

Hansen, T., Sevenius Nilsen, T., Knapstad, M., Skirbekk, V., Skogen, J., Vedaa, Ø., \& Nes, R. B. (2021). Covid-fatigued? A longitudinal study of norwegian older adults' psychosocial well-being before and during early and later stages of the COVID-19 pandemic. European Journal of Ageing. https://doi.org/ 10.1007/s10433-021-00648-0

Kelfve, S., Kivi, M., Johansson, B., \& Lindwall, M. (2020). Going web or staying paper? The use of websurveys among older people. BMC Medical Research Methodology, 20(1), 252. https://doi.org/10.1186/ s12874-020-01138-0

Kittel, B., Kritzinger, S., Boomgaarden, H., Prainsack, B., Eberl, J.-M., Kalleitner, F., Lebernegg, N. S., Partheymüller, J., Plescia, C., Schiestl, D. W., \& Schlogl, L. (2021). The austrian corona panel project: Monitoring individual and societal dynamics amidst the COVID-19 crisis. European Political Science, 20(2), 318-344. https://doi.org/10.1057/s41304-020-00294-7

Kivi, M., Hansson, I., \& Bjälkebring, P. (2021). Up and about: Older adults' well-being during the COVID19 pandemic in a swedish longitudinal study. The Journals of Gerontology. Series B, Psychological Sciences and Social Sciences, 76(2), e4-e9. https://doi.org/10.1093/geronb/gbaa084

Kotwal, A. A., Holt-Lunstad, J., Newmark, R. L., Cenzer, I., Smith, A. K., Covinsky, K. E., Escueta, D. P., Lee, J. M., \& Perissinotto, C. M. (2021). Social isolation and loneliness among san francisco bay area older adults during the COVID-19 shelter-in-place orders. Journal of the American Geriatrics Society, 69(1), 20-29. https://doi.org/10.1111/jgs.16865

Krendl, A. C., \& Perry, B. L. (2021). The impact of sheltering in place during the COVID-19 pandemic on older adults' social and mental well-being. The Journals of Gerontology. Series B, Psychological Sciences and Social Sciences, 76(2), e53-e58. https://doi.org/10.1093/geronb/gbaa110

Luchetti, M., Lee, J. H., Aschwanden, D., Sesker, A., Strickhouser, J. E., Terracciano, A., \& Sutin, A. R. (2020). The trajectory of loneliness in response to COVID-19. The American Psychologist, 75 (7), 897-908. https://doi.org/10.1037/amp0000690

Luhmann, M., \& Hawkley, L. C. (2016). Age differences in loneliness from late adolescence to oldest old age. Developmental Psychology, 52(6), 943-959. https://doi.org/10.1037/dev0000117

Macdonald, B., \& Hülür, G. (2021). Well-being and loneliness in swiss older adults during the COVID-19 pandemic: The role of social relationships. The Gerontologist, 61 (2), 240-250. https://doi.org/10.1093/ geront/gnaa194

Martín-María, N., Caballero, F. F., Lara, E., Domènech-Abella, J., Haro, J. M., Olaya, B., Ayuso-Mateos, J. L., \& Miret, M. (2021). Effects of transient and chronic loneliness on major depression in older adults: 
A longitudinal study. International Journal of Geriatric Psychiatry, 36(1), 76-85. https://doi.org/10. 1002/gps.5397

Mayerl, H., Stolz, E., \& Freidl, W. (2021). Longitudinal effects of COVID-19-related loneliness on symptoms of mental distress among older adults in austria. Public Health, 200, 56-58. https://doi.org/10.1016/j. puhe.2021.09.009

Peng, S., \& Roth, A. R. (2021). Social isolation and loneliness before and during the COVID-19 pandemic: A longitudinal study of u.s. Adults older than 50. The Journals of Gerontology: Series B. https: //doi.org/10.1093/geronb/gbab068

Peplau, L. A., \& Perlman, D. (1982). Perspectives on loneliness. In Loneliness. A sourcebook of current theory, research and therapy (pp. 1-18). John Wiley \& Sons.

Röhr, S., Reininghaus, U., \& Riedel-Heller, S. G. (2020). Mental wellbeing in the german old age population largely unaltered during COVID-19 lockdown: Results of a representative survey. BMC Geriatrics, 20(1), 489. https://doi.org/10.1186/s12877-020-01889-x

Savikko, N., Routasalo, P., Tilvis, R. S., Strandberg, T. E., \& Pitkälä, K. H. (2005). Predictors and subjective causes of loneliness in an aged population. Archives of Gerontology and Geriatrics, 41(3), 223-233. https://doi.org/10.1016/j.archger.2005.03.002

Shiovitz-Ezra, S., \& Ayalon, L. (2010). Situational versus chronic loneliness as risk factors for all-cause mortality. International Psychogeriatrics, 22(3), 455-462. https://doi.org/10.1017/S1041610209991426

Steptoe, A., Shankar, A., Demakakos, P., \& Wardle, J. (2013). Social isolation, loneliness, and all-cause mortality in older men and women. Proceedings of the National Academy of Sciences, 110(15), 57975801. https://doi.org/10.1073/pnas.1219686110

Stolz, E., Mayerl, H., \& Freidl, W. (2021). The impact of COVID-19 restriction measures on loneliness among older adults in austria. European Journal of Public Health, 31(1), 44-49. https://doi.org/10. 1093/eurpub/ckaa238

Tilburg, T. G. van, Steinmetz, S., Stolte, E., Roest, H. van der, \& Vries, D. H. de. (2021). Loneliness and mental health during the COVID-19 pandemic: A study among dutch older adults. The Journals of Gerontology: Series B, 76(7), e249-e255. https://doi.org/10.1093/geronb/gbaa111

Vehtari, A., Gelman, A., \& Gabry, J. (2017). Practical bayesian model evaluation using leave-one-out crossvalidation and WAIC. Statistics and Computing, 27(5), 1413-1432. https://doi.org/10.1007/s11222016-9696-4

Wong, S. Y. S., Zhang, D., Sit, R. W. S., Yip, B. H. K., Chung, R. Y.-N., Wong, C. K. M., Chan, D. C. C., Sun, W., Kwok, K. O., \& Mercer, S. W. (2020). Impact of COVID-19 on loneliness, mental health, and health service utilisation: A prospective cohort study of older adults with multimorbidity in primary care. The British Journal of General Practice: The Journal of the Royal College of General Practitioners, 70(700), e817-e824. https://doi.org/10.3399/bjgp20X713021 
Supplementary Table 1: Results from ordinal mixed regression models

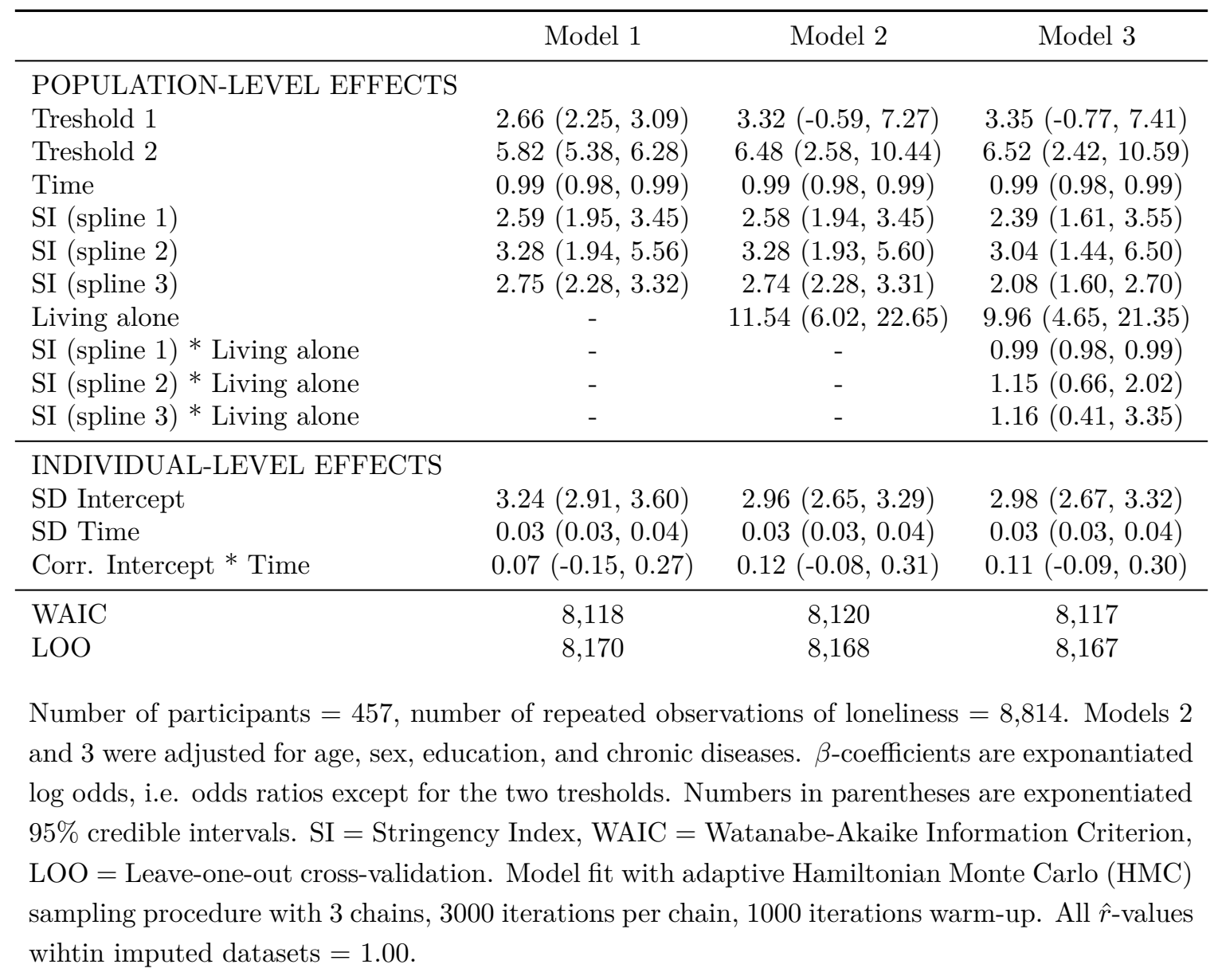

